\title{
Hospital inpatient complications and severity of illness
}

\author{
Ronald Lagoe $^{1 *}$, Anne Marie Czyz ${ }^{2}$, Joseph Bick², Shelly Littau ${ }^{1}$ \\ ${ }^{1}$ Hospital Executive Council, Syracuse, USA \\ ${ }^{2}$ St. Joseph's Hospital Health Center, Syracuse, USA \\ Email: ${ }^{*}$ Hospexcl@cnymail.com \\ Received 12 August 2013; revised 12 September 2013; accepted 12 October 2013
}

Copyright (C) 2013 Ronald Lagoe et al. This is an open access article distributed under the Creative Commons Attribution License, which permits unrestricted use, distribution, and reproduction in any medium, provided the original work is properly cited.

\begin{abstract}
This study evaluated the severity of illness of patients experiencing inpatient hospital complications in two hospitals in the metropolitan area of Syracuse, New York. It involved identification of inpatient complications by All Patients Refined (APR) severity of illness for pneumonia, clostridium difficile colitis, and urinary tract infection. Severity of illness was identified for each patient at the time of admission. The study showed that patients at the two highest levels of severity of illness, Major and Extreme, accounted for 76 - 93 percent of those with the three complications evaluated. These patients comprised less than 40 percent of the inpatient populations of the hospitals. At the same time, the study showed that only $0-23$ percent of patients at Minor or Moderate severity of illness experienced inpatient complications. These low severity of illness categories accounted for 60 percent or more of inpatients in the Syracuse hospitals. Results of the study suggested that efforts to reduce hospital inpatient complications could focus on those patients with high severity of illness. They also suggested that these efforts could largely avoid patients with low severity of illness and, as a result, save clinical and quality assurance resources in hospitals.
\end{abstract}

Keywords: Hospitalization; Hospital Complications; Quality of Care

\section{INTRODUCTION}

In recent years, increased attention has focused on health care outcomes in the United States and Europe. This attention has been generated by a number of developments concerning the data used to evaluate them, as well as to related issues such as health care expenses.

During the initial years of the twenty first century, the development of innovative tools, including computer "Corresponding author. software, for analyzing a number of outcomes indicators has led to the production and use of this information by health care providers on a scale that was not previously possible. Indicators addressed by these include hospital inpatient complications and readmissions. The resulting information has characterized these indicators quantitatively across a wide range of diagnoses and procedures in an accurate and consistent manner [1-4].

An important source of computer software for analysis of hospital outcomes has been $3 \mathrm{M}^{\mathrm{TM}}$ Health Information Systems. This organization is one of the major developers of health care software in the world. It produced the Diagnosis Related Groups during the 1980s. It has also developed the Potentially Preventable Readmissions software for analysis of that indicator.

The availability of this scale of information concerning health care outcomes has also produced greater interest in the linkages between these events and health care expenses. In the care of hospital complications and readmissions, it has helped to identify the large amounts of expenses associated with adverse outcomes $[3,5,6]$. It has also led to efforts by health care payors to link adverse outcomes with reimbursement penalties, such as the Medicare readmissions program [7].

In the United States, the increased availability of health care outcomes data has supported a wide range of efforts to evaluate these indicators at the regional and community wide levels. These efforts have included projects that link outcomes with reimbursement at the statewide and local levels, as well as programs that attempt to improve provider performance by analyzing and understanding the indicators [8-10]. The ability to manipulate large populations of administrative data has substantially increased the ability of providers to use this information in the planning and development of care within their programs and local communities.

\section{POPULATION AND METHODS}

This study involved the use of administrative data to 
evaluate the severity of illness of patients experiencing inpatient hospital complications in Syracuse, New York. It addressed this subject in two area hospitals and included data for a multiyear period.

Population and Participants

The study was developed in the metropolitan area of Syracuse, New York, which includes three acute hospitals (total discharges excluding well newborns in parentheses), St. Joseph's Hospital Health Center (25,743), Crouse Hospital $(20,719)$, Upstate University HospitalDowntown Campus (21,088), and Upstate University Hospital-Community Campus (6533). Historically, these hospitals have worked together to improve the efficiency and outcomes of health care in the community through their collaborative planning organization, the Hospital Executive Council [11].

This study was developed through a demonstration program involving the Syracuse hospitals and $3 \mathrm{M}^{\mathrm{TM}}$ Health Information Systems. The program focused on evaluating use of the $3 \mathrm{M}^{\mathrm{TM}}$ Potentially Preventable Complications (PPC) software at the community level. This software employs administrative hospital data to identify and evaluate inpatient hospital complications. It is based on application of the present on Admission indicator to the secondary diagnoses for each patient. Each of these diagnoses is identified as present on admission, not present on admission, or undetermined. Under this system, a number of diagnoses are excluded based on reasons for admission and the type of hospital service, whether medical or surgical, that a patient receives $\left(3 \mathrm{M}^{\mathrm{TM}}\right.$ Health Information Systems).

The demonstration program has involved use of the PPC software to evaluate and reduce the incidence of complications in two of the Syracuse hospitals, St. Joseph's Hospital Health Center and Crouse Hospital, since 2010. This process has included development of monthly data concerning patients assigned to a number of PPC categories, such as pneumonia, urinary tract infection, and clostridium difficile colitis, by the Hospital Executive Council. The demonstration project has focused on use of the PPC data to verify the existence of complications at the patient specific level through two activities.

Comparison of the patient specific PPC data generated through the program with hospital medical records has supported improvement of the accuracy of hospital outcomes data. During the implementation of the demonstration, the accuracy of PPC and medical records data improved at the participating hospitals.

Use of the PPC data in conjunction with hospital medical records has also made it possible to identify the extent to which planned interventions actually occurred. This process has supported the ability of hospital man- agement to plan and implement efforts to reduce complications with a high degree of effectiveness.

Analysis of Administrative Data

The first section of this study involved the use of administrative data to evaluate the relationship between hospital inpatient complications and admission severity of illness in St. Joseph's Hospital Health Center and Crouse Hospital.

For this analysis, inpatient complications were identified for pneumonia, urinary tract infection, and clostridium difficile colitis using the PPC software. Pneumonia and urinary tract infection were evaluated because these complications experienced the highest PPC frequencies in the Syracuse hospitals. Clostridium difficile colitis was evaluated because it has proven to be highly resistant to infection control programs in Syracuse and elsewhere.

For the analysis, the $3 \mathrm{M}^{\mathrm{TM}}$ All Patients Refined Diagnosis Related Groups (APR DRGs) were used to identify admission severity of illness in the Syracuse hospitals. The APR DRGs identify inpatient severity of illness based on a formula that includes the principal diagnosis, secondary diagnoses, age and other factors. Based on this information, patients are identified as experiencing Minor, Moderate, Major, or Extreme severity of illness [12]. This definition of severity of illness was used to evaluate patients with complications throughout the study.

Most importantly, severity of illness was identified for each patient at the time of inpatient admission. This procedure eliminated the potential for post admission complications to influence this indicator.

The analysis of administrative data was based on comparisons of hospital inpatient complications by frequency and percent. The focus of the study involved annual data. Quarterly comparisons were also available. The comparisons involved simple descriptive statistics.

The initial component of this analysis involved comparisons of PPC data for St. Joseph's Hospital Health Center and Crouse Hospital for January-December 2012. Frequencies and percentages were identified for each of the four severity of illness categories for pneumonia, urinary tract infection, and clostridium difficile colitis as inpatient complications. An additional analysis was developed for January-June 2013. These comparisons used the same inpatient complications as the two hospital evaluation.

The second component of the analysis involved comparisons of PPC data for St. Joseph's Hospital Health Center for January-December 2010 and 2012. This hospital was used in the analysis because it had been involved in the program throughout the demonstration period.

Analysis of Medical Record Data

The second section of the study involved the use of 
administrative data in conjunction with patient medical record data to evaluate the patient population with the highest severity of illness, those at Major and Extreme severity at St. Joseph's Hospital Health Center who received interventions under the demonstration program. This population accounted for a majority of patients who experienced pneumonia, urinary tract infection, and clostridium difficile colitis. This analysis was based on the most recent time periods available, July-December 2012 and January-June 2013.

In this section of the analysis, hospital medical record data were employed to generate additional information, concerning factors that might affect the susceptibility of the patient to complications. These factors were suggested in discussions with the staffs of the hospitals and the Hospital Executive Council. A list of these factors follows.

Patient Age by Interval

$$
\begin{aligned}
& 18-44 \text { years } \\
& 45-64 \text { years } \\
& 65-74 \text { years } \\
& 75-84 \text { years } \\
& 85 \text { years and over }
\end{aligned}
$$

Additional Diagnoses Identified in Medical Records
Renal Failure
Diabetes
Respiratory Failure
Urinary Tract Infection
Liver Failure
Depression
Heart Failure

Compromised Immune System

Discharge Status

Self Care

Home Health Care

Nursing Home

Expired

Other Factors Involving the Health Care System Ventilator Care

Transfer from Another Health Care Facility

Hospital Readmission

Infectious Disease Consult

In the development of the study, the numbers of patients with pneumonia, urinary tract infection, and clostridium difficile colitis as a complication who experienced each of these factors and study interventions were identified as a frequency and percent of the total. This information was employed to develop conclusions regarding the impact of each factor and the combined factors.

\section{RESULTS}

Results of the initial section of the study involved the use of administrative data to evaluate inpatient hospital complications by admission severity of illness. Data concerning St. Joseph's Hospital Health Center and Crouse

\begin{tabular}{|c|c|c|c|c|c|c|c|c|}
\hline & \multicolumn{4}{|c|}{ Patients at Risk } & \multicolumn{4}{|c|}{ Percent of Total } \\
\hline & \multicolumn{2}{|c|}{ With PPC } & \multicolumn{2}{|c|}{ Without PPC } & \multicolumn{2}{|c|}{ With PPC } & \multicolumn{2}{|c|}{ Without PPC } \\
\hline & SJHHC & $\mathrm{CH}$ & SJHHC & $\mathrm{CH}$ & SJHHC & $\mathrm{CH}$ & SJHHC & $\mathrm{CH}$ \\
\hline \multicolumn{9}{|c|}{ PPC 04/05-Pneumonia and Other Lung Infections } \\
\hline Minor & 2 & 0 & 5022 & 3231 & 0.95 & 0.00 & 23.04 & 24.00 \\
\hline Moderate & 21 & 6 & 8521 & 4969 & 9.95 & 6.90 & 39.09 & 36.91 \\
\hline Major & 77 & 23 & 6639 & 4041 & 36.49 & 26.44 & 30.46 & 30.02 \\
\hline Extreme & 111 & 58 & 1617 & 1220 & 52.61 & 66.67 & 7.42 & 9.06 \\
\hline Total & 211 & 87 & 21,799 & 13,461 & 100.00 & 100.01 & 100.01 & 99.99 \\
\hline \multicolumn{9}{|c|}{ PPC 15-Clostridium Difficile Colitis } \\
\hline Minor & 0 & 0 & 5024 & 3231 & 0.00 & 0.00 & 22.88 & 23.90 \\
\hline Moderate & 3 & 0 & 8539 & 4975 & 6.12 & 0.00 & 38.88 & 36.79 \\
\hline Major & 24 & 8 & 6692 & 4056 & 48.98 & 29.63 & 30.47 & 30.00 \\
\hline Extreme & 22 & 19 & 1706 & 1259 & 44.90 & 70.37 & 7.77 & 9.31 \\
\hline Total & 49 & 27 & 21,961 & 13,521 & 100.00 & 100.00 & 100.00 & 100.00 \\
\hline \multicolumn{9}{|c|}{ PPC 16-Urinary Tract Infection } \\
\hline Minor & 3 & 3 & 5021 & 3228 & 2.52 & 2.88 & 22.94 & 24.01 \\
\hline Moderate & 25 & 30 & 8517 & 4945 & 21.01 & 28.85 & 38.91 & 36.78 \\
\hline Major & 57 & 39 & 6659 & 4025 & 47.90 & 37.50 & 30.42 & 29.94 \\
\hline Extreme & 34 & 32 & 1694 & 1246 & 28.57 & 30.77 & 7.74 & 9.27 \\
\hline Total & 119 & 104 & 21,891 & 13,444 & 100.00 & 100.00 & 100.01 & 100.00 \\
\hline
\end{tabular}
Hospital for January-December 2012 are summarized in Table 1.

Table 1. Medical/Surgical Potentially Preventable Complications Selected PPC Categories by Severity of Illness St. Joseph's Hospital Health Center and Crouse Hospital January-December 2012.

Pearson correlation between percentages of patients with and without PPCs $(-0.3489)$ for St. Joseph's Hospital Health Center and $(-0.6105)$ for Crouse Hospital. 
This information in Table 1 demonstrated that, for the PPCs evaluated, the proportions of patients who experienced complications and who were at Major and Extreme admission severity of illness were substantially larger than the proportions of patients at these levels of illness who did not experience complications. For St. Joseph's Hospital Health Center, differences between these proportions ranged from 89.10 to 37.88 percent for pneumonia, from 93.88 to 38.24 percent for clostridium difficile colitis, and from 76.47 to 38.16 percent for urinary tract infection. For Crouse Hospital, they ranged from 93.11 to 39.08 percent for pneumonia, from 100.00 to 39.31 percent for clostridium difficile colitis, and from 68.27 to 39.21 percent for urinary tract infection. These differences were confirmed by negative correlations between the percent distributions of patients with and without complications by severity of illness for each of the hospitals.

This information demonstrated that the prevalence of these complications was much higher among the sickest hospital patients than among the rest of the inpatient population. It was also notable that, within these ranges, the percentages of patients at Extreme admission severity of illness who experienced complications were also substantially higher than the percentages of those who did not. At St. Joseph's Hospital Health Center, they ranged from 52.61 to 7.42 percent for pneumonia, from 44.90 to 7.77 percent for clostridium difficile colitis, and from 28.57 to 7.74 percent for urinary tract infection. At
Crouse Hospital, the differences ranged from 66.67 to 9.06 percent for pneumonia, from 70.37 to 9.31 percent for clostridium difficile colitis, and from 30.77 to 9.27 percent for urinary tract infection.

Conversely, comparisons involving proportions of patients at Minor and Moderate admission severity of illness demonstrate that the prevalence of these levels of illness was much lower in the population who experienced inpatient complications than among those who did not. At St. Joseph's Hospital Health Center, differences between these proportions ranged from 10.80 to 62.13 percent for pneumonia, from 6.12 to 61.76 percent for clostridium difficile colitis, and from 23.53 to 61.85 percent for urinary tract infection. At Crouse Hospital, the proportions ranged from 6.90 to 60.91 percent for pneumonia, from 0.00 to 60.69 percent for clostridium difficile colitis, and from 31.73 to 60.79 percent for urinary tract infection.

This information suggested that a majority of the hospital populations, who were not at high severity of illness, did not experience inpatient complications. These conclusions were also reflected in comparisons involving the individual Minor and Moderate severity categories.

The initial section of the study also included comparisons of proportions of patients who experienced inpatient complications by admission severity of illness over time. For this analysis, St. Joseph's Hospital Health Center data for 2010 and 2012 were employed. Results are summarized in Table 2.

Table 2. Medical/SURGICAL Potentially Preventable Complications Selected PPC Categories by Severity of Illness, St. Joseph's Hospital Health Center January-December 2010, 2012.

\begin{tabular}{|c|c|c|c|c|c|c|c|c|}
\hline & \multicolumn{4}{|c|}{ Patients at Risk } & \multicolumn{4}{|c|}{ Percent of Total } \\
\hline & \multicolumn{2}{|c|}{ With PPC } & \multicolumn{2}{|c|}{ Without PPC } & \multicolumn{2}{|c|}{ With PPC } & \multicolumn{2}{|c|}{ Without PPC } \\
\hline & 2010 & 2012 & 2010 & 2012 & 2010 & 2012 & 2010 & 2012 \\
\hline \multicolumn{9}{|c|}{ PPC 04/05-Pneumonia and Other Lung Infections } \\
\hline Minor & 2 & 2 & 4096 & 5022 & 0.89 & 0.95 & 22.13 & 23.04 \\
\hline Moderate & 17 & 21 & 6943 & 8521 & 7.59 & 9.95 & 37.51 & 39.09 \\
\hline Extreme & 127 & 111 & 1672 & 1617 & 56.70 & 52.61 & 9.03 & 7.42 \\
\hline Total & 224 & 211 & 18,511 & 21,799 & 100.00 & 100.00 & 100.00 & 100.00 \\
\hline \multicolumn{9}{|c|}{ PPC 15-Clostridium Difficile Colitis } \\
\hline Minor & 0 & 0 & 4098 & 5024 & 0.00 & 0.00 & 21.96 & 22.88 \\
\hline Moderate & 4 & 3 & 6956 & 8539 & 5.56 & 6.12 & 37.27 & 38.88 \\
\hline Major & 28 & 24 & 5850 & 6692 & 38.89 & 48.98 & 31.35 & 30.47 \\
\hline Total & 72 & 49 & 18,663 & 21,961 & 100.00 & 100.00 & 100.00 & 100.00 \\
\hline \multicolumn{9}{|c|}{ PPC 16-Urinary Tract Infection } \\
\hline Minor & 2 & 3 & 4096 & 5021 & 1.29 & 2.52 & 22.05 & 22.94 \\
\hline Moderate & 34 & 25 & 6926 & 8517 & 21.94 & 21.01 & 37.28 & 38.91 \\
\hline Major & 68 & 57 & 5810 & 6659 & 43.87 & 47.90 & 31.27 & 30.42 \\
\hline Extreme & 51 & 34 & 1748 & 1694 & 32.90 & 28.57 & 9.41 & 7.74 \\
\hline Total & 155 & 119 & 18,580 & 21,891 & 100.00 & 100.00 & 100.00 & 100.00 \\
\hline
\end{tabular}

Pearson correlation between percentages of patients with and without PPCs $(-0.4257)$ for 2010 and $(-0.3489)$ for 2012 . 
The information in Table 2 demonstrated that proportions of patients at Major or Extreme admission severity of illness at St. Joseph's Hospital Health Center who experienced the complications in 2010 and 2012 were very similar. In most cases, they were within a few percentage points for the two years, 91.52 and 89.10 percent for pneumonia, 94.45 and 93.88 percent of clostridium difficile colitis, and 76.77 and 76.47 percent for urinary tract infection. The proportions in the two years at the hospital were also similar for high severity of illness patients who did not experience complications, 40.36 and 37.88 percent for pneumonia, 40.78 and 38.24 percent for clostridium difficile colitis, and 40.68 and 38.16 percent for urinary tract infection.

The comparisons were also similar for low admission severity of illness patients who experienced inpatient complications at St. Joseph's Hospital Health Center in 2010 and 2012 from 8.48 and 10.90 percent for pneumonia, 5.56 and 6.12 percent for clostridium difficile colitis, and 23.23 and 23.53 percent for urinary tract infection. For low severity of illness patients who did not experience complications, proportions ranged from 59.64 to 62.13 percent for pneumonia, from 59.23 to 61.76 percent for clostridium difficile colitis and from 59.33 to 61.85 percent for urinary tract infection.

The differences between percent distributions of pa- tients with and without complications by severity of illness were confirmed by negative correlations between these populations.

A followup analysis, including data for St. Joseph's Hospital Health Center for the initial quarters of 2013 which are summarized in Table 3, suggested that the proportions of patients who experienced complications by severity of illness were consistent during the four year period. For pneumonia, patients with Major and Extreme severity of illness accounted for 93.33 percent of the total in 2013, compared with 91.52 and 89.10 percent in 2010 and 2012. For clostridium difficile colitis, they accounted for 100.0 percent of the 2013 population, compared with 94.45 and 93.38 percent in 2010 and 2012 . For urinary tract infection, the 2013 proportion was high, 90.0 - 95.0 percent, than 76.77 and 76.47 in 2010 and 2012.

The second section of the analysis focused on identification of characteristics of high admission severity of illness patients who received the program interventions but still experienced inpatient complications. These data were derived from hospital patient medical records.

The differences between percent distributions of patients with and without complications by severity of illness were confirmed by negative correlations between these populations.

Table 3. Medical/Surgical Potentially Preventable Complications Selected PPC Categories by Severity of Illness, St. Joseph's Hospital Health Center January-June 2013.

\begin{tabular}{|c|c|c|c|c|c|c|c|c|}
\hline & \multicolumn{2}{|c|}{ Patients at Risk w PPC } & \multicolumn{2}{|c|}{ Patients at Risk w/o PPC } & \multicolumn{2}{|c|}{ Patients at Risk w PPC } & \multicolumn{2}{|c|}{ Patients at Risk w/o PPC } \\
\hline & Jan-Mar & Apr-Jun & Jan-Mar & Apr-Jun & Jan-Mar & Apr-Jun & Jan-Mar & Apr-Jun \\
\hline \multicolumn{9}{|c|}{ PPCs 04/05_-Pneumonia and Other Lung Infections } \\
\hline Minor & 0 & 0 & 1168 & 1133 & 0.00 & 0.00 & 22.23 & 20.97 \\
\hline Moderate & 4 & 3 & 2059 & 2081 & 6.67 & 6.67 & 39.19 & 38.53 \\
\hline Major & 21 & 19 & 1597 & 1788 & 35.00 & 42.22 & 30.40 & 33.10 \\
\hline Extreme & 35 & 23 & 430 & 400 & 58.33 & 51.11 & 8.18 & 7.40 \\
\hline Total & 60 & 45 & 5254 & 5402 & 100.00 & 100.00 & 100.00 & 100.00 \\
\hline \multicolumn{9}{|c|}{ PPC 15-Clostridium Difficile Colitis } \\
\hline Minor & 0 & 0 & 1168 & 1133 & 0.00 & 0.00 & 22.07 & 21.15 \\
\hline Moderate & 0 & 0 & 2063 & 2078 & 0.00 & 0.00 & 38.98 & 38.79 \\
\hline Major & 10 & 6 & 1608 & 1769 & 47.62 & 60.00 & 30.38 & 33.02 \\
\hline Extreme & 11 & 4 & 454 & 377 & 52.38 & 40.00 & 8.58 & 7.04 \\
\hline Total & 21 & 10 & 5293 & 5357 & 100.00 & 100.00 & 100.01 & 100.00 \\
\hline \multicolumn{9}{|c|}{ PPC 16-Urinary Tract Infection } \\
\hline Minor & 0 & 0 & 1168 & 1133 & 0.00 & 0.00 & 22.06 & 21.01 \\
\hline Moderate & 2 & 1 & 2061 & 2081 & 10.00 & 4.17 & 38.93 & 38.60 \\
\hline Major & 11 & 17 & 1607 & 1782 & 55.00 & 70.83 & 30.36 & 33.05 \\
\hline Extreme & 7 & 6 & 458 & 396 & 35.00 & 25.00 & 8.65 & 7.34 \\
\hline Total & 20 & 24 & 5294 & 5392 & 100.00 & 100.00 & 100.00 & 100.00 \\
\hline
\end{tabular}

Pearson correlation between percentages of patients with and without PPCs $(-0.4565)$ for January-March and $(-0.1407)$ for April-June. 
The data used in this portion of the analysis were summarized by age, selected clinical categories, and use of the health system for patients who experienced interventions. This information was generated for two time periods, July-December 2012 and January-June 2013 at St. Joseph's Hospital Health Center. Information for the pneumonia, clostridium difficile colitis, and urinary tract infection inpatient complications are summarized in Table 4 .

The data indicated that most of these patients were aged 65 years or more (42 of 58 for pneumonia, 38 of 58 for clostridium difficile colitis and 37 of 52 for urinary tract infection). In each case, a relatively small proportion of the patients were ages 85 years and over, indicating that they were elderly, but not frail elderly. The only population with at least 20 percent at this level were those with clostridium difficile colitis between January and June 2013.

The data concerning clinical conditions demonstrated that patients with all three complications were seriously ill. The highest incidence of organ failure involved pneumonia during 2012 and 2013 for respiratory failure (13 of 21 patients and 12 of 37), renal failure (12 of 21 and 12 of 37), and heart failure (10 of 21 and 11 of 37), as well as clostridium difficile colitis in 2013 for renal failure (19), respiratory failure (12), and heart failure (10). All three groups of patients with complications experienced relatively high levels of diabetes and functional disorders including pneumonia for 2013, and clostridium difficile colitis and urinary tract infection for

Table 4. Inpatient Medical/Surgical Potentially Preventable Complications Major and Extreme Severity of Illness St. Joseph's Hospital Health Center July-December 2012, January-June 2013.

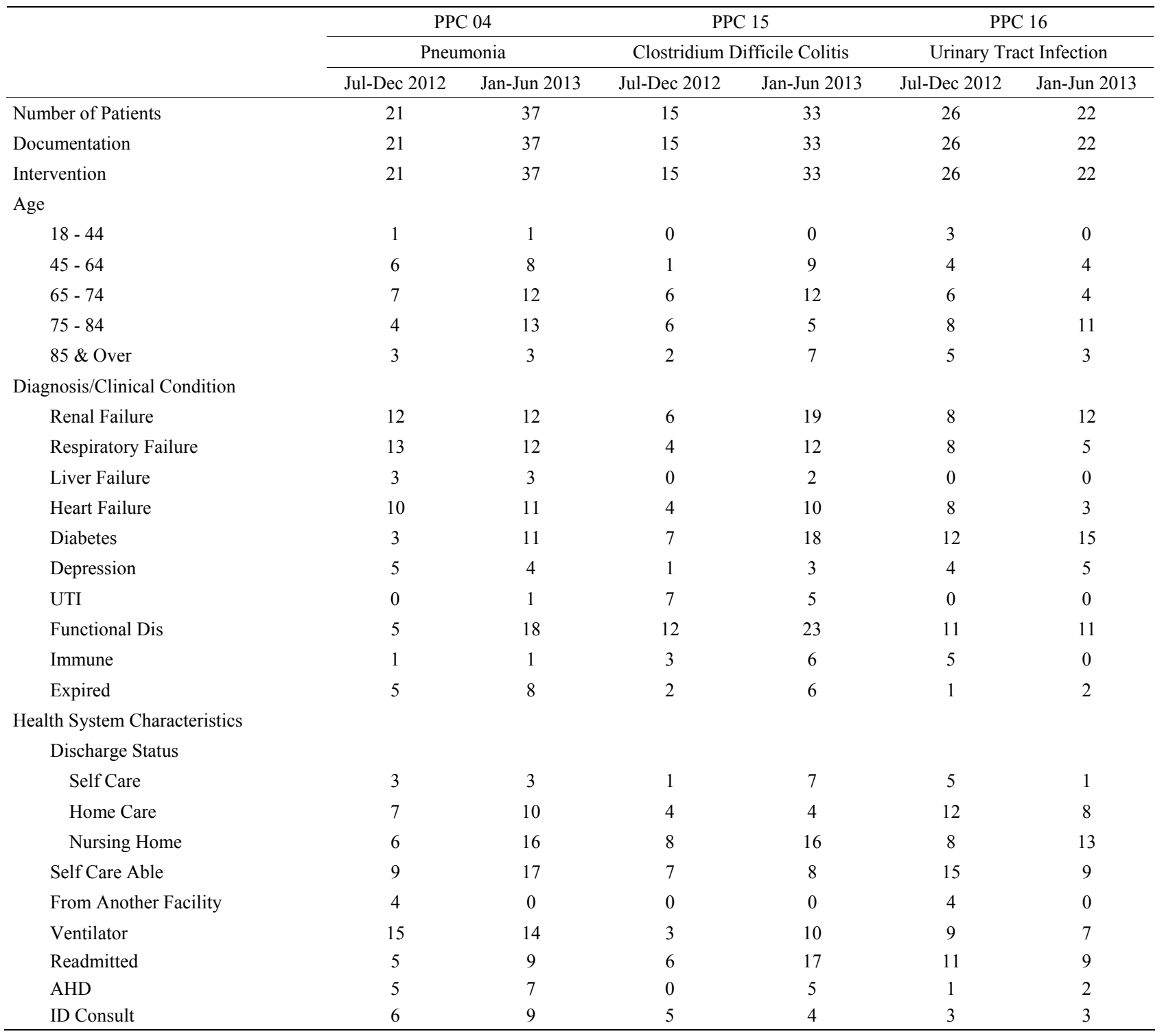


both years. The data also indicated that, despite these diagnoses, comparatively few patients expired during the hospitalizations during which the complications occurred. For both six month periods, these included 13 patients for pneumonia, 8 patients with clostridium difficile colitis, and 3 patients with urinary tract infection.

Most of the patients in each of the populations with complications had extensive experience with services in the health care system. Most of the pneumonia patients (13 of 21 and 26 of 37), the clostridium difficile colitis (12 of 15 and 20 of 33), and urinary tract infection (20 of 26 and 21 of 22) were discharged to long term care services including home health agencies and nursing homes. Many of them received ventilator care in the hospital and/or were readmitted after previous hospitalizations.

\section{DISCUSSION}

This study evaluated associations between three frequently encountered inpatient hospital complications and admission severity of illness in two large urban hospitals in the metropolitan area of Syracuse, New York. It demonstrated that distributions of patients who experienced and did not experience complications by severity were markedly different.

The study showed that patients at the highest levels of admission severity of illness, Major and Extreme, accounted for percentages of patients with complications that were two to three times higher than those of patients without complications. Those at Major and Extreme severity comprised large majorities, 76 - 93 percent of patients with the three complications evaluated.

Patients with Minor or Moderate severity of illness comprised only $0-23$ percent of those with complications. Patients with the lowest levels of admission severity of illness, Minor and Moderate, accounted for percentages of patients with complications that were 10 - 37 percent of those for patients without complications.

The study data demonstrated that these associations between outcomes and severity of illness were consistent between hospitals and over time. They existed in two of the three Syracuse hospitals that participated in the study and in the hospital with the longest running participation over a multiyear period.

This information suggested that efforts to address inpatient complications in hospitals need to focus on patients with the highest admission severity of illness. Among the four severity of illness categories in the Syracuse hospitals, these patients were at the greatest risk of developing adverse outcomes. Almost all of the patients with complications identified were at Major or Extreme severity.

This information also suggested that efforts to address inpatient complications could largely avoid patients with Minor or Moderate severity of illness. Because these patients accounted for a majority of those at risk, this could result in a substantial savings of clinical and quality assurance resources.

It should be emphasized that the analyses of inpatient complications by severity of illness were based on administrative data abstracted from patient medical records. The severity of illness categories applied in this analysis was also based on administrative data. The analysis also was limited to two large hospitals in a single metropolitan area.

Data from patient medical records, in the second section of the analysis, suggested that the patients who experienced inpatient complications were seriously ill, but were also survivors. With respect to age level, a majority of the patients who experienced each of the complications and interventions were elderly, ages $65-84$ years. The data also demonstrated that they experienced a number of serious illnesses, including organ failure, and had extensive experience with the health care system. At the same time, the data showed that relatively few of these patients expired.

The patient record data also demonstrated that most of those at high admission severity of illness still experienced inpatient complications, even after they received interventions developed to prevent them. These experiences suggest that a new level of prevention would probably need to be developed to avoid these adverse outcomes.

These points suggest another issue with respect to this population, that all complications are probably not preventable, especially in patients with high severity of illness. This point is supported with the administrative data from the study, which indicated that proportions of high severity patients with complications were consistent between hospitals and over time. It was reinforced by the patient record data.

All of this information demonstrates the need for additional research on the subject of patients who experience inpatient complications and high level of illness. Such research can help identify clinical interventions with the most promise for addressing the needs of these patients. It can also delineate the capabilities of current and future approaches, as well as the limits of preventability for these conditions.

\section{REFERENCES}

[1] Iezzoni, L.I., Daley, J., Heeren, T., Foley, S.M., Fisher, E.S., Duncan, C., Hughes, J.S. and Coffman, G.A. (1994) Identifying complications of care using administrative data. Medical Care, 32, 700-715. http://dx.doi.org/10.1097/00005650-199407000-00004

[2] Hughes, J.S., Averill, R.F., Goldfield, N.I., Gay, J., Muldoon, J., McCullough, E.C. and Xiang, J. (2006) Identifying potentially preventable complications using a pre- 
sent on admissions indicator. Health Care Financing Review, 27, 63-82.

[3] Fuller, R.L., McCullough, E.C., Bao, M. and Averill, R.F. (2009) Estimating the costs of potentially preventable hospital acquired complications. Health Care Financing Review, 30, 17-32.

[4] Zegers, M., deBruijne, M.C., Wagner, C., Hoonhout, L.H.F., Waaijman, R. and Smits, M. (2009) Adverse events and potentially preventable deaths in Dutch Hospitals: results of a retrospective review study. Quality and Safety in Health Care, 18, 297-302. http://dx.doi.org/10.1136/qshc.2007.025924

[5] Averill, R.F., McCullough, E.C., Hughes, J.S., Goldfield, N.I., Vertrees, J.C. and Fuller, R.L. (2009) Redesigning the Medicare inpatient PPS to reduce payments for hospitals with high readmission rates. Health Care Financing Review, 30, 1-15.

[6] Hoonhout, L.H., deBruijne, M.C., Wagner, C., Zegers, M., Waaijman, R., Spreeuwenberg, P., Asscheman, H., van der Wal, G. and Tulder van, M.W. (2009) Direct medical costs of adverse events in Dutch hospitals. BMC Health Services Research, 9, 27. http://dx.doi.org/10.1186/1472-6963-9-27
[7] Rau, J. (2012) Medicare to penalize 2211 hospitals for excess readmissions. Kaiser Health News.

[8] Calikoglu, S., Murray, R. and Feeney, D. (2012) Hospital pay for performance programs in Maryland produced strong results-Including reduced hospital acquired conditions. Health Affairs, 31, 2649-2657. http://dx.doi.org/10.1377/hlthaff.2012.0357

[9] Lagoe, R.J., Murphy, M.E. and Johnson, P.J. (2011) Inpatient hospital complications and lengths of stay: A short report. BMC Research Notes, 4, 135. http://dx.doi.org/10.1186/1756-0500-4-135

[10] Lagoe, R.J. and Westert, G.P. (2010) Evaluation of hospital inpatient complications: A planning approach. BMC Health Services Research, 10, 200. http://dx.doi.org/10.1186/1472-6963-10-200

[11] Lagoe, R., Pasinski, T., Kronenberg, P., Quinn, T. and Schaengold, P. (2006) Linking health services at the community level. Canada Health Care Quarterly, 9, 60-65. http://dx.doi.org/10.12927/hcq..18229

[12] Averill, R.F., Goldfield, N.I. and Muldoon, J. (2002) A closer look at all patients refined DRGs. Journal of AHIMA, 10, 46-50. 